JJ GLAZIER

Clinical professor of medicine,

Wayne State University, Detroit,

United States

\section{Fluid assessment is critical in acute kidney injury (AKI)}

Editor - Muniraju and colleagues highlight the need for education around recognition and definition of acute kidney injury (AKI) at junior doctor level (Clin Med June 2012 pp216-21), supporting Ali and Lewington's findings that trainee doctors were frequently unable to define AKI. ${ }^{1}$ However, this phenomenon is not restricted to junior doctors. In a survey of 159 doctors in the West Midlands, only $30 \%$ of general physician consultants and registrars $(n=39)$ were able to correctly define AKI. In our qualitative analysis of perceived learning needs in AKI, doctors at all levels asked the question 'how much fluid should we give in AKI?' This implies a belief that fluid requirements are static, when in fact it is a dynamic process requiring repeated clinical assessment.

As such, the importance of correctly determining the amount of fluid required to resuscitate the patient with AKI is critical. Junior doctors are often the first people to assess such patients and may prescribe inadequate volumes. ${ }^{2}$ Our survey showed that foundation year (FY) doctors assessed the jugular venous pulse (JVP) and postural blood pressure (BP) less frequently than did nephrologists (JVP 55\% vs $100 \%$, $\mathrm{Chi}^{2} \mathrm{p}=0.0008$; postural BP $6.7 \%$ vs $41 \%$, $\left.\mathrm{Chi}^{2} \mathrm{p}=0.0014\right)$. Even nephrologists did not agree on the best method of determining volume status.

Although the evidence base for individual clinical skills in determining intravascular fluid is sparse, there is negligible harm in performing a comprehensive clinical examination compared with invasive monitoring such as measuring the central venous pressure. By using just skin temperature and JVP, shock can be correctly differentiated between septic, cardiogenic and hypovolemic causes in $76 \%$ of cases. ${ }^{3}$ Hence by performing a comprehensive assessment it is likely that this accuracy could be improved.

In our study, 18 separate terms were used to define the routine performed, ranging from 'fluid assessment' and 'volume status' to 'hydration status' and 'circulation'. When there is such variation in terminology it is unsurprising that doctors at all levels miss vital clinical skills that can add a great deal to the practical management of patients with AKI.

We suggest that a standardised routine of fluid assessment be taught and assessed at undergraduate level, on a par with the 'cardiovascular examination' routine that stu- dents hone throughout medical school. FY1 doctors would be equipped with a robust tool to correctly prescribe fluids that would be applicable to patients under any discipline, with any diagnosis.

JACK BOND

Clinical teaching fellow

SIMON FLETCHER

Consultant nephrologist

Department of Renal Medicine, University Hospitals Coventry and Warwickshire, UK

\section{References}

1 Ali MN, Lewington AJ. Invited manuscript poster on renal-related education American Society of Nephrology, Nov. 16-21, 2010. Do medical trainees receive adequate training in the management of acute kidney injury? Ren Fail 2011;33:669-71.

2 Matheson NJ, Irani SR, Irani A. Early intervention in acute renal failure: evidence of inadequate intravenous fluid treatment in UK hospitals. BMJ 2006;333:551.

3 Vazquez R, Gheorghe C, Kaufman D, Manthous CA. Accuracy of bedside physical examination in distinguishing categories of shock: a pilot study. J Hosp Med, 2010;5:471. 